\title{
Changes of Glycoprotein Patterns in Sera of Humans under Stress
}

\author{
Karmela Barišić ${ }^{1}$, Gordan Lauc ${ }^{1}$, Jerka Dumić ${ }^{1}$, Mladen Pavlović ${ }^{2}$ and Mirna Flögel ${ }^{1}$ \\ 1 Department of Biochemistry and Molecular Biology, Faculty of Pharmacy and Biochemistry, \\ University of Zagreb, Zagreb, Croatia \\ 2 Institute for Medical Research and Occupational Health, Zagreb, Croatia
}

Summary: Stress exhibits adverse effects on many vital processes in which glycoproteins play a significant role (e.g. cell-cell/matrix interactions, immune response, neoplastic growth, implantation, prenatal development), yet only scarce attention has been directed towards studying stress induced changes in glycoprotein patterns. Using SDS-electrophoresis, blotting and digoxigenin-labelled lectins (Sambucus nigra agglutinin, Galanthus nivalis agglutinin, Datura stramonium agglutinin, Maackia amurensis agglutinin and peanut (Arachis hypogaea) agglutinin), sera were analysed from 30 individuals chosen randomly from a severely stressed population of 309 male volunteers with no specific medical symptoms. Significant changes were found in glycoprotein pattern and content, compared with healthy controls of matching age and sex. Occasionally minor non-specific deviations from the reference values for several analytes (haemoglobin, glucose, bilirubin and alanine aminotransferase) were detected in the tested group, but glycoprotein GP45 $\left(M_{\mathrm{r}}=45000\right)$, detected by Datura stramonium agglutinin and Sambucus nigra agglutinin, appeared in $96.7 \%$ of samples of the stressed population. The same population also revealed an approximately 500-fold increase of GP37 in comparison with the control sera. These results suggest that stress, as a non-specific syndrome, induces specific biochemical changes, which could be of diagnostic relevance as risk makers before any more serious symptoms of stress-related consequences have developed.

\section{Introduction}

Glycoproteins are molecules which contain more structural information than any other molecules in the human body. According to the current knowledge of the underlying biosynthetic machinery, the structural carbohydrate complexity arises from the multiplicity of enzymes involved in their synthesis (1) suggesting functional significance of the information stored in the carbohydrate parts of glycoproteins $(2,3)$.

Glycoproteins are known to play a key role in many vital processes from fertilization, blastocyst implantation and prenatal development, to immune response and cancer (4). Evidence for their involvement in the stress response is growing $(5,6)$ and recently it was even demonstrated that some oligosaccharide structures can have beneficial effects in murine traumatic shock (7).

Stress and depressive symptoms have been associated with the development and course of many human diseases from simple virus infections to cancer $(8,9)$. Many of these diseases can be associated with a stress-induced decrease in the immune reponse, and a notable number of studies have addressed this problem $(10,11)$. Significant effects have been found in the stress-induced suppression of natural killer cytotoxicity (12), and production of specific antibodies (13).
Exposure to stress during pregnancy have severe adverse consequences for child development. When rats were exposed to the foot-shock or swimming stress during early pregnancies, a significant decrease of body weight gain and increased offspring mortality were detected $(14,15)$. When stress was experienced during the pre-implantation stage, it prevented implantation and caused complete abolition of pregnancy $(16,17)$. Epidemiological studies in humans have also indicated that psychological stress causes a significant increase of habitual abortions, lower birth-weight and a higher rate of pregnancy abnormalities $(18-20)$.

In this study we analysed changes in the sera of individuals who underwent intensive stress while imprisoned in war camps of former Yugoslavia. The life conditions in these camps are reported to have been harsh $(21,22)$ and a number of medical (23), psychological (24) and immunological (25) problems were present among detainees (tab. 1). Standard biochemical quantities were also analysed (tab. 2). Deviations from the standard values were found in some detainees, but none of the tests proved to be a common and specific marker $(26,27)$.

As mentioned above, glycoproteins have an important role in many stress-related processes. However, only few studies have been undertaken to evaluate stress-re- 
lated changes of specific glycoproteins and lectins $(28-34)$.

Lectins, natural specific receptors for glycoproteins are useful tools for specific detection and characterization of glycoproteins in vitro $(35,36)$. We used a set of five specific lectins listed in table 3 to identify individual glycoproteins in normal (control) sera and in sera from detainees.

\section{Materials and Methods}

\section{Materials}

5-Bromo-4-chloro-3-indolylphosphate, $p$-nitro blue tetrazolium and bovine serum albumin were purchased from Sigma (St. Louis, MO), Immobilon PVDF membrane from Millipore (Bedford, MA), digoxigenin-labelled Galanthus nivalis, peanut (Arachis hypogaea), Sambucus nigra, Maachia amurensis and Datura stramonutum agglutinins (lectins), and alkaline phosphatase-conjugated anti-digoxigenin $\mathrm{F}(\mathrm{ab})_{2}$ fragments from Boehringer Mannheim (Mannheim).

\section{Study population}

Sera from individuals, imprisoned for at least 90 days in detention camps in the area of former Yugoslavia (eastern Slavonia), were

Tab. 1 Health problems in war prisoners liberated from concentration camps $(23,26)$

\begin{tabular}{ll}
\hline Problem & Frequency (\%) \\
\hline Rash & 5 \\
Albuminuria & 7 \\
Leukocyturia & 6 \\
Headaches & 63 \\
Dizziness & 70 \\
Disturbed sleep & 57 \\
Nightmares & 32 \\
\hline
\end{tabular}

Tab. 2 Deviations form normal biochemical values in prisoners of war (26)

\begin{tabular}{lc}
\hline Result & $\begin{array}{l}\text { Percentage } \\
\text { of }\end{array}$ \\
\hline Decreased haemoglobin $(<139 \mathrm{~g} / \mathrm{l})$ & $24 \%$ \\
Increased bilirubin $(>20 \mu \mathrm{mol} / \mathrm{l})$ & $13 \%$ \\
Increased creatinine $(>110 \mu \mathrm{mol} / \mathrm{l})$ & $8.2 \%$ \\
Increased alanine aminotransferase $(>35 \mathrm{IU} / \mathrm{l})$ & $19 \%$ \\
Decreased glucose $(<3 \mathrm{mmol} / \mathrm{l})$ & $0.7 \%$ \\
Increased glucose $(>6 \mathrm{mmol} / \mathrm{l})$ & $6.9 \%$ \\
\hline
\end{tabular}

Tab. 3 Specificity of lectins

\begin{tabular}{lll}
\hline Lectin & Source & Specificity \\
\hline GNA & Galanthus nivalis & $\begin{array}{l}\text { Man- } \alpha(1,3) \text {, Man- } \alpha(1,6) \text {, or } \\
\text { Man- } \alpha(1,3)-M a n\end{array}$ \\
SNA & Sambucus nigra & Sia- $\alpha(2,6)-$ Gal \\
MAA & Maackia amurensis & Sia- $\alpha(2,3)-$ Gal \\
PNA & Peanut & Gal- $\beta(1,3)-G a l N A c$ \\
& (Arachis hypogaea) & \\
DSA & Datura stramonitm & Gal- $\beta(1,4)-$ GlcNAc \\
\hline
\end{tabular}

examined after their release in March 1992. For this study 30 detainees (males, age 19-45) were selected randomly from the group of 309 volunteers (informed consent) with no apparent infectious or other disease (or significant physical injuries) detected by medical examination. Sera were donated willingly by detainees within three days after release from camps and stored at $-80^{\circ} \mathrm{C}$ until analysed. The control group $(n=9)$ of sera was taken from apparently healthy volunteers (of matching age and geographic origin).

\section{Electrophoresis and blotting}

Serum proteins were separated electrophoretically in $12 \%$ SDSpolyacrylamide slab gels as described by Laemmli (37). After electrophoresis, proteins were transferted onto Immobilon PVDF membranes in a semi-dry apparatus (Pharmacia, Sweden) according to Towbin et al. (38). After blotting, membranes were blocked overnight with $30 \mathrm{~g} / 1$ bovine serum albumin, and developed with digoxigenin-labelled lectins in the following dilutions: $1: 1000$ for Sambucus nigra, Galanthus nivalis and Datura stramonium agglutinins, $1: 200$ for Maackia amurensis agglutinin and $1: 100$ for peanut agglutinin (35). The formed glycoprotein-lectin complexes were detected with anti-digoxigenin $\mathrm{F}(\mathrm{ab})_{2}$ fragments conjugated with alkaline phosphatase and visualized with $0.02 \mathrm{~g} / 1$ 5-bromo-4chloro-3-indolylphosphate and $0.04 \mathrm{~g} / \mathrm{l}$ nitro blue tetrazolium in 50 $\mathrm{mmol} / \mathrm{Tr}$ Trs $/ \mathrm{HCl}, \mathrm{pH}=8.5,100 \mathrm{mmol} / / \mathrm{NaCl}, 5 \mathrm{mmol} / / \mathrm{MgCl}_{2}$

Amounts of individual glycoproteins were calculated by scanning and integrating spots on the membrane. Integration was performed with GelScan XI software (Pharmacia) by fitting Gaussian curves into scanning results on the basis of horizontal background. Intensities of individual glycoprotein bands were expressed in relative units as defined in the GelScan software (area units).

Protein concentrations were determined using the biuret method (39).

\section{Results}

Galactose-specific peanut agglutinin, mannose specific Galanthus nivalis agglutinin, and sialic acid-specific Maackia amurensis agglutinin did not show any significant differences in the resulting binding patterns between sera from detainees and control individuals (fig. 1).

In contrast, Sambucus nigra and Datura stramoniumreactive glycoproteins in the sera of detainees showed
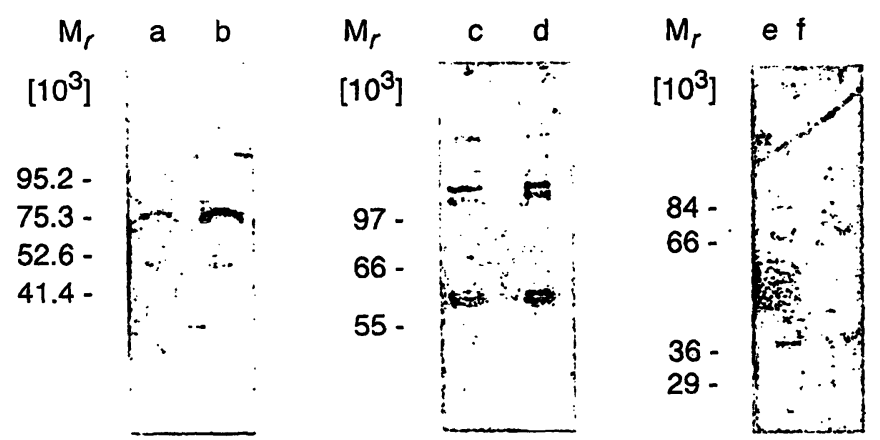

Fig. 1 Patterns of glycoproteins in control sera $(a, c, e)$ and in sera from individuals under stress $(b, d, f)$. Serum proteins $(20$ $\mu \mathrm{g}$ of total protein per well) were separated on $12 \%$ SDS PAGE, transferred to Immobilon PVDF membrane and detected with $\mathrm{Ga}$ lanthus nivalis agglutinin ( $(a, b)$, Maackia amurensis agglutinin (c, $d)$, and peanut agglutinin $(e, f)$. There were no differences in the glycoproteins reactive with these three lectins which could be correlated with exposure to stress. The double band which sometimes appeared with the Galanthus nivalis agglutinin appeared with similar frequencies in both populations. 
Tab. 4 Relative amounts ${ }^{a}$ of stress induced glycoproteins. Presented values are averages from 30 stress-samples (detainees) and
9 control individuals. Standard deviations are shown in parentheses.

\begin{tabular}{lllll}
\hline Glycoprotein & \multicolumn{2}{l}{ Detection with Datura stramonium lectin } & & \multicolumn{2}{l}{ Detection with Sambucus nigra lectin } \\
\cline { 2 - 4 } & Stress & Control & Stress & Control \\
\hline 37000 & $<0.01(-)$ & $<0.01(-)$ & $3.533(0.986)$ & $0.087(0.059)$ \\
45000 & $0.645(0.231)$ & $<0.01(-)$ & $2.107(0.574)$ & $<0.01(-)$ \\
\hline
\end{tabular}

a Amounts of glycoproteins are expressed in the relative units (area) as defined in the Pharmacia GelScan ${ }^{\circledR}$ software.

significant alterations in comparison with control sera (tab. 4, figs. 2 and 3). A random example of a normal lectin-binding pattern for Gal- $\beta(1,4)$-GlcNAc specific Datura stramonium agglutinin is shown on figure $2 b$. Only one major glycoprotein band, of apparent mass of 50000 , is visible. Figure 2a shows a typical example of a Datura stramonium agglutinin-binding pattern in sera from detainees. In addition to the 50000 band, there is

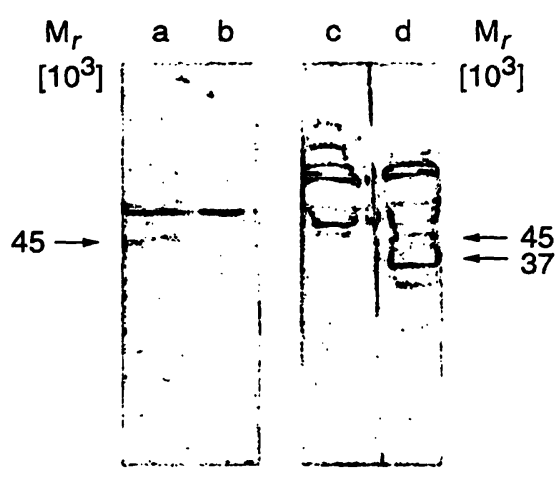

Fig. 2 An example of stress-induced changes of lectin binding patterns in sera from a detainee $(a, d)$ compared to a control individual $(b, c)$. Serum proteins $(20 \mu \mathrm{g}$ of total protein per well) were separated on $12 \%$ SDS PAGE and transferred to Immobilon PVDF membrane. Glycoproteins were detected using Datura stramonium (a, b) and Sambucus nigra agglutinin (c, d). Two major alterations were detected: (i) appearance of a novel $M_{\mathrm{r}}=45000$ band (GP45) which was detected with both Datura stramonium and Sambucus nigra agglutinin; and (ii) 500-fold increase in concentration of $M_{\mathrm{r}}$ $=37000$ Sambucus nigra agglutinin-reactive glycoprotein (GP37).

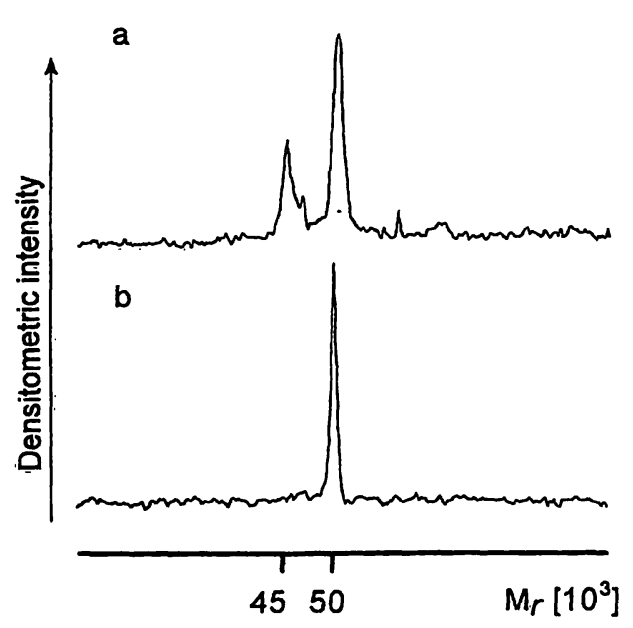

Fig. 3 Comparisons of Datura stramonium (a, b) and Sambucus nigra agglutinin $(c, d)$ lectin binding patterns in sera from stressed $(a, d)$ and control subject $(b, c)$. The figure represents densitometric an another clearly visible glycoprotein with an apparent molecular mass of 45000 . The incidence of appearance of this glycoprotein (GP45) in samples originating from detainees exceeded $96 \%$ (found in 29 out of 30 detainees). GP45 was completely absent from all examined control sera, thus suggesting that it is induced by stress.

Analysis of serum glycoproteins by Sia- $\alpha(2,6)-G a l$ specific Sambucus nigra lectin (fig. 2) also revealed significant alterations in detainees (d) compared with the control group (c). Although more glycoproteins are recognized by Sambucus nigra agglutinin than by Datura stramonium agglutinin, two distinct changes are clearly visible. The most pronounced one is the appearance of an additional glycoprotein $\left(M_{\mathrm{r}}=45000\right)$, which probably corresponds to the above mentioned Datura stramonium agglutinin-reactive glycoprotein of the same size. Comparison with the normal lectin-binding pattern also showed a significant (more than 500-fold) increase in the amount of the glycoprotein of approximate molecular mass 37000 (GP37) in sera of detainees (tab. 4, figs. 2 and 3$)$.

\section{Discussion}

In the presented study we analysed glycoprotein patterns in sera from normal individuals and from individuals

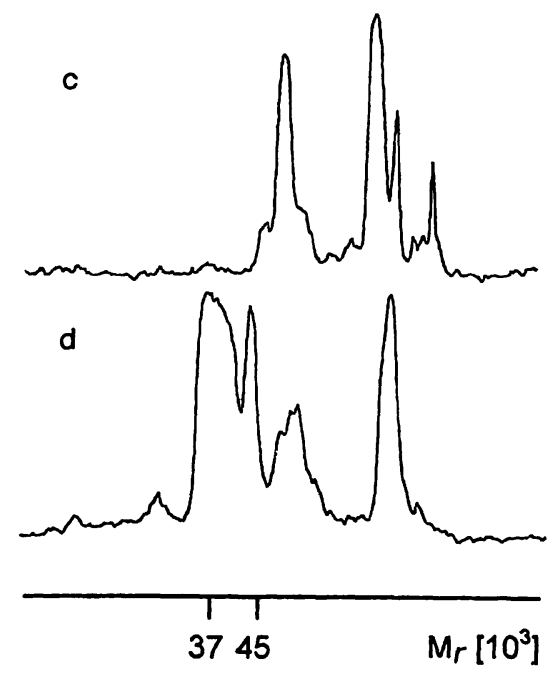

scans of the blots from figure 2. For detailed explanation see Matcrials and Methods. 
detained in war prisoner camps for at least 90 days, being exposed to complex inescapable stress including food deprivation, intense fear, and possible maltreatment. Our aim was to find a specific biochemical response of the human organism to this kind of stress. Previously reported results of basic biochemical tests showed deviations from normal values in some detainees, but none of the analysed properties was shown to be a specific marker present in all detainees $(26,27)$.

We found two major changes of serum glycoproteins in nearly all detainees (96.7\%):

(i) appearance of a novel $M_{\mathrm{r}}=45000$ glycoprotein (figs. 2 and 3); and

(ii) a 500-fold increase in the amount of GP37.

Both of these glycoproteins were virtually absent from all control sera and present in all but one analysed detainee serum. The nearly ubiquitous presence of these glycoproteins in detainees, irrespectively of their physical status, individual variability, differences in treatment and medical history, and absence of the same glycoproteins in control individuals, strongly indicate that these glycoproteins are a consequence of exposure to intense stress.

On the basis of lectin-binding patterns, and the assumption that 45000 glycoproteins recognized by Sambucus nigra agglutinin and Datura stramonium agglutinin are the same protein, it is possible to partly identify the carbohydrate parts of these glycoproteins. GP45 was recognized by galactose-specific Datura stramonium aggluti-

\section{References}

1. Kornfeld R, Kornfeld S. Assembly of asparagine linked oligosaccharides. Annu Rev Biochem 1985; 54:631-64.

2. Drickamer $\mathrm{K}$. Two distinct classes of carbohydrate-recognition domains in animal lectins. J Biol Chem 1988; 263:9557-60.

3. Lee YC. Sweet and sharply: ligands for animal lectins. Biochem Soc Trans 1993; 21:460-3.

4. Warren L. Bound carbohydrates in nature. Cambridge: Cambridge University Press, 1994.

5. Henle KJ, Nagle WA. Inhibition of heat shock protein synthesis and protein glycosylation by stepdown heating. Exp Cell Res 1991; 196:184-91.

6. Henle KJ, Kaushal GP, Nagle WA, Nolen GT. Prompt protein glycosylation during acute heat stress. Exp Cell Res 1993; 207:245-51.

7. Skurk C, Buerke M, Guo JP, Paulson J, Lefer AM. Sialyl Lewis $^{x}$-containing oligosaccharide exerts beneficial effects in $\mathrm{mu}$ rine traumatic shock. Am J Physiol 1994; 267:H2124-31.

8. Weiner $\mathrm{H}$. The behavioral biology of stress and psychosomatic medicine. In: Brown MR, Koob GF, Rivier C, editors. Stress: neurobiology and neuroendocrinology. New York: Dekker, 1991:22-51.

9. Bassao AM, Depiante-Depaoli M, Molina VA. Chronic variable stress facilitates tumoral growth: reversal by imipramine administration. Life Sci 1992; 50:1789-96.

10. Ader R, Cohen N, Felten D. Psychoneuroimmunology: interactions between the nervous system and the immune system. Lancet 1995 ; 345:99-103. nin, and by sialic acid-specific Sambucus nigra agglutinin, while it was not recognized by mannose-specific Galanthus nivalis agglutinin, galactose-specific peanut agglutinin (galactose linked in a different way from the recognized by Datura stramonium agglutinin), and sialic acid-specific Maackia amurensis ágglutinin (sialic acid linked in a different way from that recognized by Sambucus nigra agglutinin). It seems that GP45 contains branched oligosaccharides with at least two different termini. One terminus is characterized by galactose, possibly bound by a $\beta(1,4)$ glycosidic linkage to $\mathrm{N}$-acetylglucosamine, but certainly not through a $\beta(1,3)$ linkage to $\mathrm{N}$-acetyl-galactosamine. Another terminus possesses sialic acid, probably bound to galactose through a $\alpha(2,6)$ glycosidic linkage. Lack of recognition of this glycoprotein by the mannose-specific Galanthus nivalis agglutinin implies that it does not contain terminal mannose residues and is not a high-mannose glycoprotein.

On the basis of the positive reaction of GP37 with Sambucus nigra agglutinin and its negative reaction with Galanthus nivalis agglutinin, GP37 is also not a highmannose glycoprotein and contains at least one terminus with sialic acid, probably bound to galactose through a $\alpha(2,6)$ glycosidic linkage. Further studies aimed at the purification of GP37 and GP45 and the determination of their structure and possible functions are in progress.

\section{Acknowledgements}

This study was supported by the Ministry of Science and Technology of the Republic of Croatia, Grant \# 1-07-102.

11. Irwin M. Stress-induced immune suppression. Role of the autonomic nervous system. Ann NY Acad Sci 1993; 697:20318.

12. Irwin $M$, Hauger $R L$, Britton $K$. Benzodiazepines antagonize central corticotropin releasing hormone-induced suppression of natural killer cell activity. Brain Res 1993; 631:114-8.

13. Laudenslager ML, Fleshner M, Hofstadter P, Held SE, Simons L, Maier SF. Suppression of specific antibody production by inescapable shock: stability under varying conditions. Brain Behav Immunol 1988; 2:92-101.

14. Pollard I. Effects of stress administered during pregnancy on reproductive capacity and subsequent development of the offsprings of rats: prolonged effects on the litters of a second pregnancy. J Endocrinol 1983; 100:301-6.

15. Guo A, Nappi RE, Criscuolo M, Ficarra G, Amram A, Trentini GP, et al. Effect of chronic intermittent stress on rat pregnancy and postnatal development. Eur J Obstet Gynecol Reprod Biol 1993; 51:41-5.

16. Euker JS, Riegle GD. Effects of stress on pregnancy in the rat. J Reprod Fertil 1973; 34:343-6.

17. De Catanzaro D. Effect of predator exposure upon early pregnancy in mice. Physiol Behav 1989; 43:691-6.

18. Shaw JA, Wheeler P, Margan DW. Mother infant relations and weight gain in the first month of life. J Am Acad Child Psychol $1970 ; 9: 428-44$.

19. Blomberg S. Influence of maternal. distress during pregnancy on fetal malformations. Acta Psychiatr Scand 1980; 62:31530 . 
20. Homer J, James SA, Siegel E. Work-related psychosocial stress and risk of pre-term, low birth weight delivery. Am J Public Health 1990; 80:173-7.

21. Mazowiecki T. Report of special rapporteur of the Commission on Human Rights on the situation of human rights in the territory of former Yugoslavia. In: Report to the General Assembly of the UN. New York: United Nations; 1992:18-19. 47th General Assembly Session, agenda item 98c.

22. Nowotny $Z$. Manjaca: how the Yugoslav Federal Army treats the prisoners. Croatian Med J 1992; 2 Suppl:90-2.

23. Kuzman I, Borcic D. Medical examination of the Pows from the chetniks concentrations camp Glina. Acta Med Croat 1993; 47 Suppl:93-6.

24. DeZan D, Anic N, Klein E. Psychic status of the Manjaca camp prisoners. Croatian Med J 1992; 2 Suppl:97-100.

25. Dekaris D, Scabioncello A, Mazuran R, Rabatic S, SvobodaBeusan I, Ljubic Racunica N, Tomasic J. Multiple changes of immunological parameters in prisoners of war. Assessment after release froma camp in Manjaca, Bosnia. J Am Med Ass 1993; 270:595-9.

26. Jeren T, Begovac J. Basic laboratory tests of ex-POWs. Acta Med Croat 1993; 47 Suppl:23-5.

27. Pavlovic M, Zavalic M, Corovic N, Stilinovic L, Malinar M. Loss of body mass in ex-prisoners of war. Eur J Clin Nutr 1993; 47:808-14.

28. Tsukada H, Seino Y, Ueda S, Uchino H, Sakai M. Influence of water-immersion stress on synthesis of mucus glycoprotein in the rat gastric mucosa. Scand J Gastroenterol 1989; 162 Suppl:19-22.

29. Bardosi L, Bardosi A, Hendrys M, Gabius HJ. Reduced expression of mannose-specific receptors on murine peripheral blood polymorphonuclear leukocytes following prolonged anaesthesia with different inhalation agents. Acta Anaesthesiol Scand 1990; 34:286-90.

30. Bardosi L, Bardosi A, Gabius HJ. Changes of expression of endogenous sugar receptors by polymorphonuclear leukocytes after prolonged anaesthesia and surgery. Can J Anaesth 1992; 39:143-50.

31. Kitajima M, Mogi M, Kiuchi T, Shimizu A, Nakajima M, Oshima A, et al. Alteration of gastric mucosal glycoprotein (lec- tin-binding pattern) in gastric mucosa in stress. A light and electron microscopic study. J Clin Gastroenterol 1990; $12: \mathrm{S} 1-7$

32. Lauc G, Seve A, Hubert J, Flögel M, Müller WEG, Schröder HC. HnRNP CBP35-CBP67 interaction during stress response and ageing. Mech Age Dev 1993; 70:227-37.

33. Lauc G, Flögel M, Diehl-Seifert B, Schröder HC, Müller WEG. Identification and purification of a stress associated nuclear carbohydrate binding protein $M_{r} 33,000$ ) from rat liver by application of a new photoreactive carbohydrate probe. Glycoconjugate J 1995; 11:541-9.

34. Heffer-Lauc $M$, Latin V, Breyer B, Flögel M, Müller WEG, Lauc G. Glycoprotein and ganglioside changes in human trophoblasts after exposure to pulsed doppler ultrasound. Ultrasound Med Biol 1995; 21:579-89.

35. Lis $\mathrm{H}$, Sharon $\mathrm{N}$. Lectins as molecules and as tools. Annu Rev Biochem 1986; 55:35-67.

36. Haselbeck A, Schickander E, von der Eltz H, Hösel W. Structural characterization of glycoprotein carbohydrate chains by using digoxigenin-labeled lectins on blots. Analyt Biochem 1990; 147:222-9.

37. Laemmli UK. Cleavage of structural proteins during the assembly of the head bacteriophage T4. Nature 1970; 227:680-5.

38. Towbin H, Staehelin T, Gordon J. Electrophoretic transfer of proteins from polyacrylamide gels to nitrocellulose sheets: procedure and some applications. Proc Natl Acad Sci USA 1979; 76:4350-7.

39. Reinhold JG. Total protein, albumin and globulin. Standard methods of clinical chemistry, vol. 1. New York: Academic press, Inc, 1953.

Received July 20/September 22, 1995

Corresponding author: Mirna Flögel, Department of Biochemistry and Molecular Biology, Faculty of Pharmacy and Biochemistry, University of Zagreb, Domagojeva 2, HR-1000 Zagreb, Croatia 
